\title{
The Application of Flipped Classroom Based on the Micro-class in College English
}

\author{
Yi Lu, a and Mu Sun ${ }^{2, b}$ \\ ${ }^{1}$ Jilin Business and Technology College, No.1666 Calun Lake Street, Changchun, Jilin Province, \\ China \\ ${ }^{2}$ Changchun University of Science and Technology, No.7089 Weixing Road, Changchun, Jilin \\ Province, China

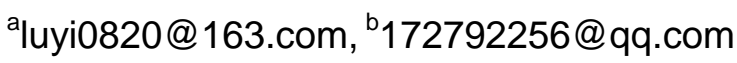

Keywords: Micro-class; Flipped classroom; Teaching model; Features; Application

\begin{abstract}
Micro-class and flipped classroom are the new teaching models with the help of modern technology. They receive the widespread attention and the high praise from both teachers and learners as soon as they come out. This paper aims to introduce the new teaching model of flipped classroom based on micro-class, analyze the characteristics and at last discuss the application of the new teaching model to college English teaching.
\end{abstract}

\section{Introduction}

Micro-class and flipped classroom are the new teaching models which have attracted great attention recent years. They break the time and space limits of traditional English learning, and meet the requirements of modern times and most people's learning habits. [1] They will become a new model for college course learning in the information age. The application of flipped classroom based on micro-class in college English conforms to the development of times and adjustment of students' learning model and it improves students' learning interest and effects. [2]

\section{The Concept and Origin of Micro-Class and Flipped Classroom}

Micro-Class. Micro-class is the short form of Micro video network class, and it takes the micro video as the major carrier, and it was designed and developed to explain the knowledge points in an online video course. [3] It has the following characteristics:

The length of the class should be 5-10 minutes, and even shorter, because the time for attention focused is only 10 minutes, see Fig. 1.

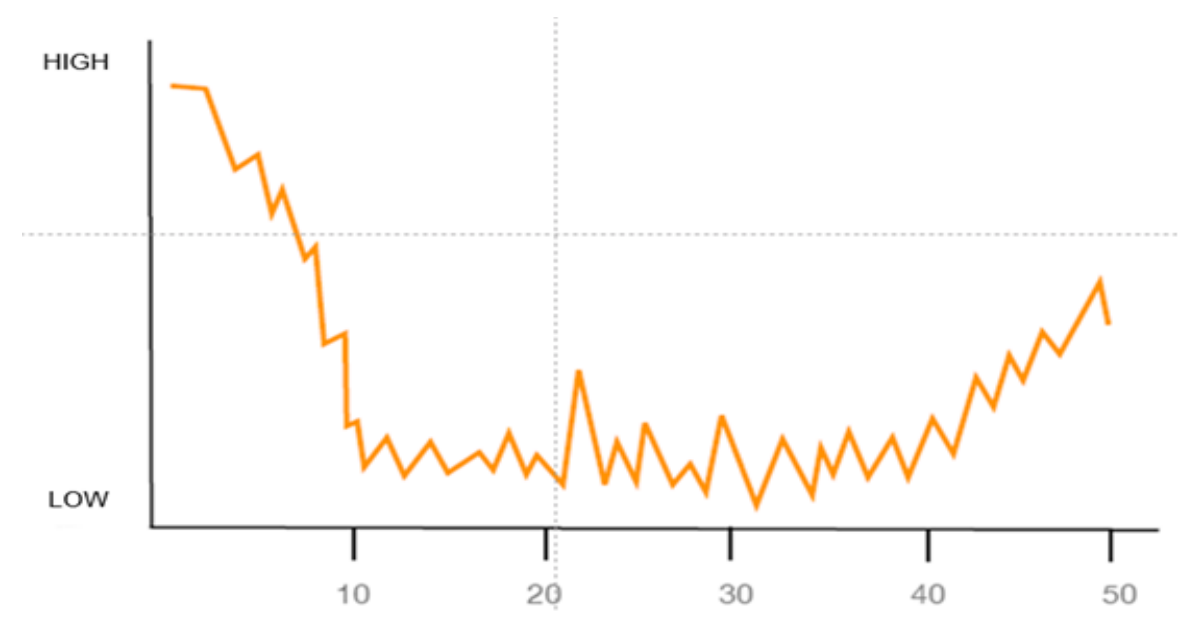

Figure 1. Class teaching time (min)

It takes video as the core carrier and has various materials to make up. The contents teachers will 
teach are recorded in the video, and combined with multimedia materials for learners to study. This form is easy to accept for most learners.

It should be easy to get and transmit. Micro-class is not a course teaching, but a detailed explanation for certain knowledge point, and attracts watchers' attention in a very short time and masters the contents at the same time. [4] The video material should be accessible and easy to transmit, learners can watch and learn it as they need and share it with other people who also want to learn.

Flipped Classroom. Flipped Classroom origins in the spring of 2007, Johnason Berman and Allen Sams, the chemistry teachers try to solve the problem that some of their students could not go to school on time because of the weather or long distance and missed a lot of classes, so they fell behind, and could not follow the teacher and top students. The two teachers began to make a video of lessons with the help of PowerPoint and uploaded it in the internet, to make up missed lessons for the students who were absent from class. [5] At that time, YouTube has just started. And then, they reform their lesson for watching instruction videos at home, and save more time for finishing assignment together and solving students' difficulties in their experiment in the class. Soon, the online instruction videos were accepted by more and more people and it has spread far and wide. In 2011, Salman Khan made a speech in TED (Technology Entertainment Design). In the speech, he mentioned that there were many free teaching video he uploaded which were deeply loved by many students and these teaching videos had received good teaching effects in several experimental school. Some teachers were inspired and tried to reform their former teaching model, and they asked students to watch video at night, and focused on finishing the assignment and interaction between teachers and students. This method flipped the traditional classroom's planning of "teachers teach in the class, and students finish assignment after class", so it is called "flipped classroom".

\section{The Teaching Model of Flipped Classroom Based on Micro-Class}

We try to design a concept diagram of the teaching model of flipped classroom based on the micro-class, see Fig. 2, [6]:

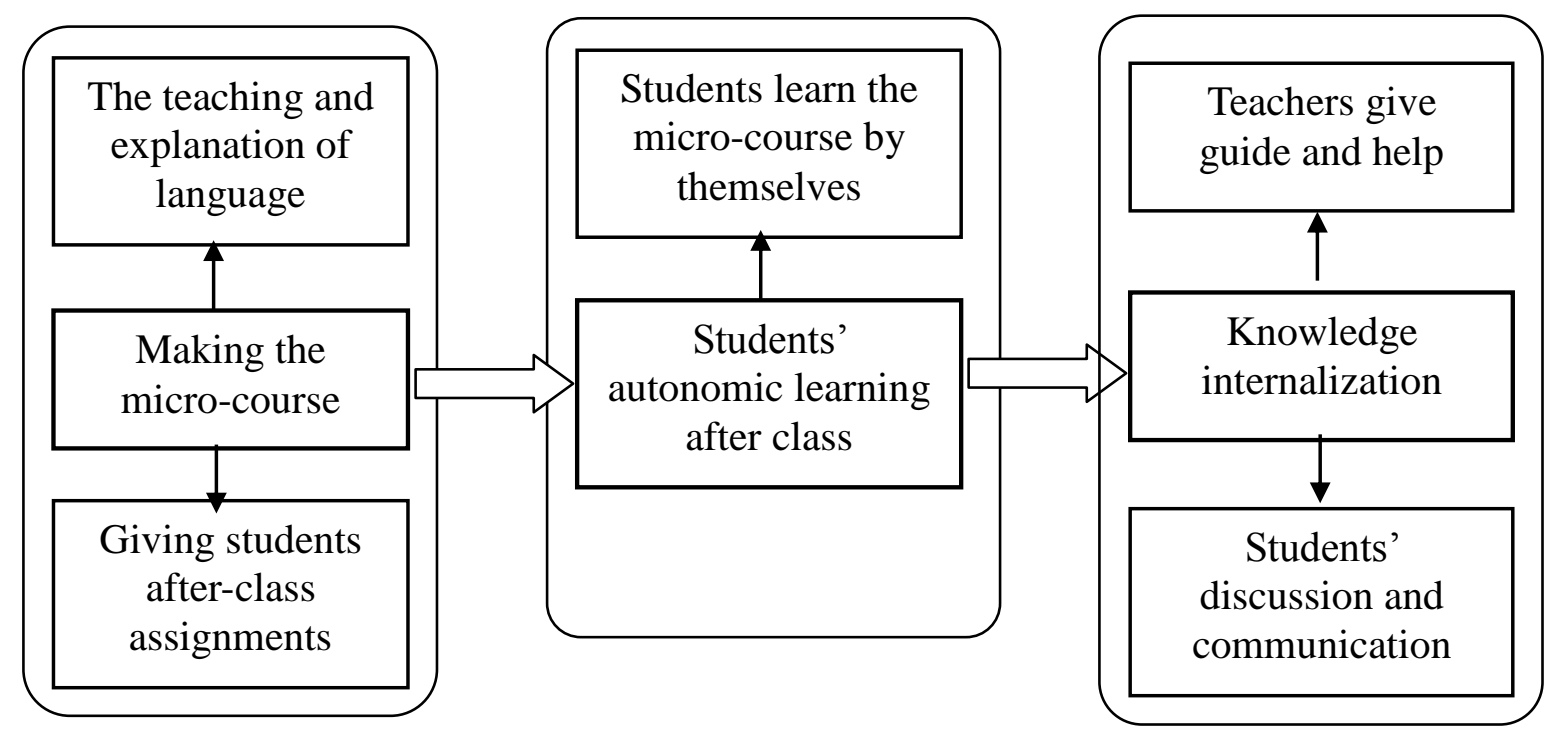

Figure 2. The concept diagram of the new teaching model

And the teaching procedures should be as followed:

1. Teachers make lecture video (micro-class);

2. Students watch teachers' lecture video after class;

3. Students write down the doubts and difficulties in the process of self-learning; 
4. Teachers and students communicate the doubts and difficulties face to face in the class;

5. Teachers and students finish the assignment in the textbook together;

6. Effective and efficient study.

In the procedure, 1, 2 are the prerequisite, 3, 4, 5 are the process, and 6 is the result.

\section{The Features of Flipped Classroom}

The Change of Teacher's Role. Firstly, teacher changes from the initiator in the traditional class to the promoter and guider of students. Teachers are not the controller of class, and students' main body role has been fully reflected. But it doesn't mean teachers' main body function weakens, instead, it should be strengthened. [7] Teachers should be skilled in the strategies for organizing some classroom activities, for example, how to organize project learning, how to plan team learning, how to design games for learning, how to devise a role-play, etc.

Secondly, teachers changed from a transmitter of teaching materials into a designer of video learning material and a provider of relevant educational materials. Teachers should provide necessary materials, for example, the video for teaching the relevant knowledge, teacher software, and other resources related to the content and topic of the coming lecture in the internet, so that students can have a fully understanding of the knowledge they are going to learn. When students need help, teachers will provide them necessary help. So teachers are the scaffolds for students to get resources, use the resources and process information and then apply the knowledge into real situation. [7]

The Change of Students' Role. In the individualized learning, students set up their own leaning plan, they can choose the time and place to study, and they can decide the learning contents and how much they learn. Students are the main body in the process, and not the passive receipt of the knowledge in the traditional classroom. Students have the knowledge themselves before class, so in the class they try to understand and absorb what they learnt deeply through group learning and cooperative learning. Students change from the knowledge-consumer to the knowledge-producer, [8] and students who learn fast can help other students learn well, take a part of teaching, and this experience will promote their learning interests.

The Redistribution of Class Time. In the class, teachers' instructing time decreases, and leaves more time for students to have learning activities. That's another core character for flipped classroom. In the model of flipped classroom, the contents which teachers plan to instruct have been already learnt by students through modern network technology before class. So in the class, there will be more interaction time for the teachers and students, actually the interaction process helps students understand, apply and internalize the knowledge. It lengthens the learning time, and improves the learning efficiency.

\section{The Application of Flipped Classroom in College English}

Students' Listening, Wring and Interpreting Ability Improves. After a period time of experimental teaching, compared with traditional college English teaching, students' integrated ability improved noticeably. The reason is that the knowledge students learnt by automatic learning is more than what teachers told them, and the effect is better. In the teaching model of flipped classroom, students listen to English, and study English by reading books and magazines, by surfing the internet automatically, and they will find problems in knowledge and methods in the process, in the class, they will communication these puzzles with their teachers and peers, teachers will give detailed and deep explanations for better understanding, and give students effective methods and recommendation for their further learning. And they can discuss with classmates what learning materials are good, for example, which movie is suitable for listening and interesting, which book and magazine are good, etc. Teachers can give students some writing and interpreting work, in the class, teaching the skills and techniques by analyzing and improving their work. Students can discuss with peers and learn something valuable from teachers and peers. By using this method, students' listening, writing and interpreting ability improved a lot. 
The Ability of Speaking and Reading Improves. In the traditional speaking class, teachers say something about the task, and give students some time to prepare their topic, or let students have some discussion. The disadvantage is students' practicing time is very short and limited. In the model of flipped classroom, topic has been given, and everybody should have a presentation. They will prepare lots of work and practice their oral English before class. Class time is their presentation time, and teachers give them advice to improve their speaking contents and skills. [9] After a period of practicing, everybody will find their improvement and they will have more confidence to go further. In preparing the speaking materials, they will read more books, newspapers and magazines, and the amount of their extensive reading increased. In the reading class, teachers will give some deep expatiation for the parts which are difficult to understand and apply in some intensive reading passages, and these explanations help students read more difficult passages.

Automatic Learning Ability Increases. In the flipped classroom, students are the main body, so everyone in the class should have a good preparation before class, if they don't do that, they will fail in the exam, because teachers' explanation will based on you learnt before class. In this model, students are forced to learn, but after a period of time, they will feel good and improved by self-learning, and they will get s sense of satisfaction from their own efforts. Then the passive learning changes into active and automatic learning gradually.

Students' Degree of Recognition for the New Teaching Model Increases. In the experiment of practicing the model of flipped classroom, students think flipped classroom model is obviously much better than the traditional models, and give a great recognition for this model. Most students think the flipped classroom model gives them more automatic learning space. In the process of automatic learning, they learn more extensive English knowledge in the internet, such as the development history of English, the origin of some word, the cultural background of some festival, etc. They enrich their knowledge, and at the same time, it greatly raises their interests for leaning English. Besides, the model of filliped classroom gives them a better opportunity to show themselves, and they have more time and opportunities to practice their oral English, to express their own views and to have a role-play. They take an active part in the classroom activities, and they generally like this teaching model, they will have a continuous thinking about the questions and raise their own questions, so their learning autonomy increases.

\section{Conclusion}

The teaching model of flipped classroom based on micro-class can help students learn automatically, raise the study interaction and build their confidence of learning English. The application of it in college English teaching proves effective and efficient.

\section{References}

[1] Lu Haiyan, The Feasibility Analysis of the Application of Flipped Classroom in College English Teaching, J, Foreign Language Electrochemical Education, 7 (2014) 33-36.

[2] Zhang Jinlei, Wang Ying, Zhang Baohui, Research for Flipped Classroom Teaching Model, J. Distance Learing Journal, 4(2012) 43-45.

[3] Guan Zhongke, Micro-course, J. China Information and Technology Education,17(2011) 15-16.

[4] Liu Shuxiang, A Discussion on College Multimedia Teaching Quality, J. Theory Research, 2 (2013)18-19.

[5] Li Jiahou, The Meaning and Development of Micro-class, J. Information Technology Education, 4 (2013) 10-12.

[6] Jiao Jianli, The Application and Influence of Micro-class, J. Technology Education, 5 (2013) 30-32.

[7] Bergmann, J. \& A. Sams, Flipping the Classroom, San Bruno: Tech \& Learning, 2012. 
[8] Brunsell, E. \& M. Horejsi, A Flipped Classroom in Action, Washington: The Science Teacher, 2013.

[9] Milman, N.B., The Flipped Classroom Strategy: What is it and How Can it Best be Used?, Greenwich: Distance Learning, 2012.

[10] http://www.viaton.com.cn 